\title{
VIEWPOINT
}

\section{Regenerative agriculture for food and climate}

\author{
Rattan Lal
}

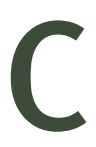
an regenerative agriculture (RA) produce an adequate amount of nutritious food for the growing and increasingly affluent world population while also reducing and offsetting some anthropogenic emissions? The question may be reframed: how can RA be adapted to produce enough food, be a negative emission technology, and advance Sustainable Development Goals of the United Nations (2015)? System-based RA reconciles the need of producing adequate and nutritious food with the necessity of restoring the environment, making farming a solution to environmental issues. It encompasses a wide range of farming and grazing practices aimed at restoration and sustainable management of soil health through sequestration of soil organic carbon $(\mathrm{C})$. There is no one-size-fitsall practice for diverse soils and ecoregions. RA comprises system-based conservation agriculture (CA), which includes no-till farming in conjunction with residue mulching, cover cropping, integrated nutrient and pest management, complex rotations, and integration of crops with trees and livestock (figure 1) (Lal 2015). RA is all inclusive, and its site-specific package(s) must be finetuned in the context of biophysical factors and the human dimensions. RA is soilcentric rather than seed-centric and is based on the premise that "health of soil, plants, animals, and humans is one and indivisible" (Howard 1943; Howard and Howard 1945). In the present context of climate change and environmental issues, it is appropriate to extend the concept by stating that the health of soil, plants, animals, people, and environment is one and indivisible. The expanded concept, based on the realization of the living soil (Balfour 1943), is specifically pertient in the era of COVID-19 (Lal 2020). The goal is to enhance soil organic matter (SOM) content and strengthen coupled biogeochemical cycling of $\mathrm{C}$ with water, nitrogen $(\mathrm{N})$, phosphorus $(\mathrm{P})$, sulfur $(\mathrm{S})$, and other elements (Lal 2010), along with strengthening disease resistance capacity of soil (Howard 1921). The soil-centric approach is focused on obtaining

\section{Figure 1}

Basic tenets of regenerative agriculture designed to draw carbon dioxide from the atmosphere. Specific packages of practices depend on site-specific biophysical environments and the human dimensions. INM = integrated nutrient management. IPM = integrated pest management. SRI = system of rice intensification.

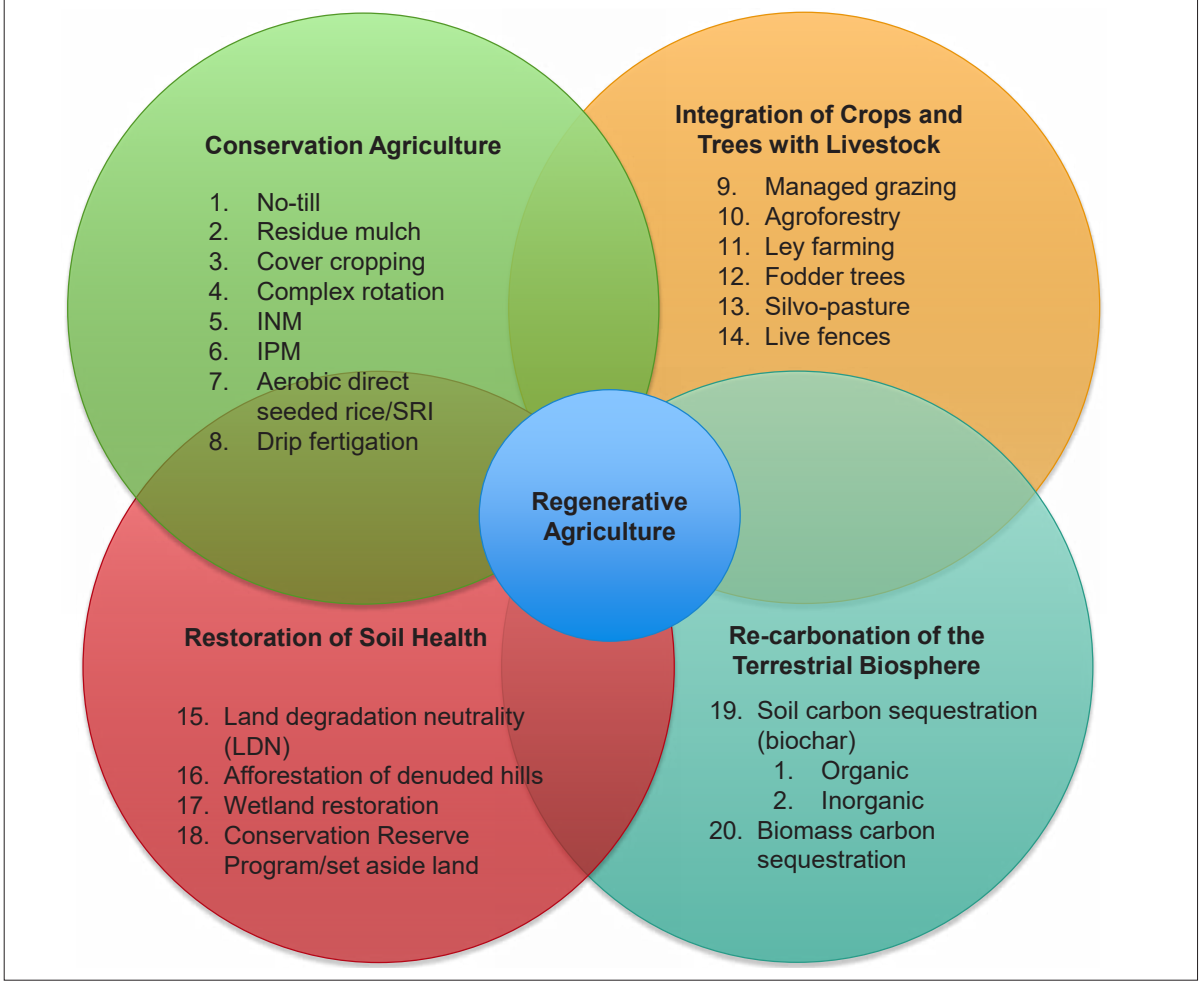

an optimum yield sustained on a long-term basis and with minimal dependence on agrochemicals. It contrasts with the conventional approach of obtaining high yields on a shortterm basis with heavy and indiscriminate use of chemical fertilizers, pesticides, tillage, and other energy-based inputs. Therefore, an appropriate question is not whether RA works or not, but how to make it work under site-specific conditions, including biophysical, social, economic, and the human dimensions. Recent advances in system-based approaches to adapting CA have improved application, enhanced global adoption, and increased the rate of adoption (Kassam et al. 2019).

\section{BASIC PRINCIPLES OF REGENERATIVE AGRICULTURE}

Whereas scientific debate is essential to ensuring quality and credibility, understanding the basic issues being deliberated is critical to maintaining objectivity. Global agriculture is already producing enough food to feed 10 billion people. However, about $30 \%$ of all food produced is wasted. It is thus important to break the vicious circle of produce, waste, degrade, pollute, and produce more. Therefore, the goal of RA is to apply the concept of more from less (McAfee 2019) to agriculture and produce more from less (Lal 2013): less land area, less input of chemicals, less use of water, less emission of greenhouse gases, less risk of soil degradation, and less use of energy-based inputs (table 1). The strategy is to spare land and resources for nature. Wasting food and polluting the environment are crimes against nature.

Rattan Lal is a distinguished university professor of soil science and is the director of the Carbon Management and Sequestration Center, The Ohio State University, Columbus, Ohio.

Received June 20, 2020. 


\section{Table 1}

Potential and aims of regenerative agriculture.

\begin{tabular}{|c|c|}
\hline Parameter & Expectations and outputs \\
\hline Agronomic yield and productivity & Optimum and sustainable \\
\hline Inputs of chemicals & Supplemental, as and when needed \\
\hline Resource use & Produce more per unit of land, water, energy \\
\hline Global warming & $\begin{array}{l}\text { Positive soil/ecosystem carbon budget in accord with the } 4 \text { per } 1,000 \text { initiative, resilience to drought/ } \\
\text { heat waves and extreme events, minimal emissions of methane }\left(\mathrm{CH}_{4}\right) \text {, nitrous oxide }\left(\mathrm{N}_{2} \mathrm{O}\right)\end{array}$ \\
\hline Profitability & Optimal and sustained over time \\
\hline Soil degradation, land desertification & Reversed, and focused on land degradation neutrality \\
\hline Food quality & Nutrition-sensitive agriculture \\
\hline Environment quality & Making farming integral to restoring and enhancing the environment \\
\hline Incentivization & Payments for ecosystem services based on societal value of natural resources \\
\hline Legislation & Soil Quality Act to complement the Clean Air Act and Clean Water Act \\
\hline
\end{tabular}

Therefore, RA is based on the premise of 1. Managing soil fertility by enhancing SOM content, biological $\mathrm{N}$ fixation, and recycling of nutrients rather than by indiscriminate inputs of chemical fertilizers

2. Improving soil structure by increasing activity and species diversity of biota (e.g., earthworms and microorganisms) and prolific plant roots rather than by plowing

3. Increasing availability of green water by conserving precipitation, reducing losses by runoff and evaporation, moderating soil temperature, and encouraging deep root systems

4. Controlling water and wind erosion through preventative measures of maintaining a continuous groundcover, cover cropping, and CA rather than by curative land forming and engineering structures

5. Managing soil acidification and elemental imbalance by biofertilizers (e.g., compost, manure, mycorrhiza) rather than by indiscriminate dumping of chemicals

6. Enhancing water infiltration rate by reducing crusting, compaction, hard-setting, and desiccation through retention of residue mulch, cover cropping, and creation of bio-pores through bioturbation of the rhizosphere

\section{GREEN REVOLUTION OF THE 21ST CENTURY}

The Green Revolution of the 21st century based on the concepts of RA must be

1. Soil-based, through enhancement and sustainable management of soil health by managing SOM content and strengthening mechanisms of elemental/nutrient recycling and increasing soil resilience to climate change
2. Ecosystem-based, through enhancement of eco-efficiency that minimizes losses, enhances use efficiency of inherent and applied resources, and minimizes dependence on external inputs

3. Knowledge-based by using modern science and managerial skills, which restore soil health and strengthen ecosystem services for humans and nature 4. Based on the Law of Return (Howard 1943), which states, replace what is removed, respond wisely to what is altered, predict what alterations may occur through anthropogenic/natural perturbations, and adopt practices that restore and enhance soil health

5. Focused on creating a positive soil and ecosystem $\mathrm{C}$ budget so that the terrestrial $\mathrm{C}$ pool is increasing over time until the sink capacity is filled, its permanence assured, risks of leakage minimized, and the terrestrial biosphere recarbonized

\section{TRANSLATING SCIENCE INTO ACTION}

Identification and formulation of policy are critical to translating science into action. Implementation of a "Soil Quality Act" (Lal 2019) is essential to complementing the existing Air Quality Act and Water Quality Act, and harnessing benefits of the soil-water-air nexus. The Soil Quality Act, aimed at making agriculture a solution to environmental issues, will also incentivize farmers through payments for ecosystem services such as sequestering of $\mathrm{C}$ in soil and vegetation (terrestrial biosphere), improving quality and renewability of water resources, strengthening biodiversity, and making agriculture nutrition-sensitive. Payments for ecosystem services must be transparent, just, fair, and based on the societal value of C, water, biodiversity, and other natural resources.

\section{REFERENCES}

Balfour, E.B. 1943.The Living Soil. London, UK: Faber and Faber.

Howard, A. 1921. Influence of soil factors on disease resistance.Annals of Applied Biology 7(4):373-389.

Howard, A. 1943. An agricultural testament. Nature 147(3733):590-591.

Howard, A., and L.E. Howard. 1945. Farming or Gardening for Health or Disease (Published later as The Soil Health: A Study of Organic Agriculture, 2010.) London, UK: Faber and Faber.

Kassam, A., T. Friedrich, and R. Derpsch. 2019. Global spread of conservation agriculture. International Journal of Environmental Studies 76(1):29-51. https://doi.org/10.1080/00207233 .2018 .1494927$.

Lal, R. 2010. Managing soils and ecosystems for mitigating anthropogenic carbon emissions and advancing global food security. BioScience 60(9):708-721.

Lal, R. 2013. Food security in a changing climate. Ecohydrology \& Hydrobiology 13(1):8-21.

Lal, R. 2015. A system approach to conservation agriculture. Journal of Soil and Water Conservation 70(4):82A-88A. https://doi. org/10.2489/jswc.70.4.82A.

Lal, R. 2019. Rights-of-Soil. Journal of Soil and Water Conservation 74(4):81A-84A. https://doi. org/10.2489/jswc.74.4.81A.

Lal, R. 2020. Soil science beyond COVID-19. Journal of Soil and Water Conservation 75(4):79A-81A. https://doi.org/10.2489/jswc.2020.0408A.

McAfee, A. 2019. More from Less: The Surprising Story of How We Learned to Prosper Using Fewer Resources-And What Happens Next. New York: Scribner.

United Nations. 2015. Sustainable Development, 17 Goals. New York: United Nations, Department of Economics and Social Affairs. 